\title{
Development of extruded snack by using multigrain with pineapple pomace powder
}

\section{Pranayjeet Shinde and Surekha Dabhade}

Received : 13.07.2018; Revised : 15.08.2018; Accepted : 01.09.2018

See end of the Paper for authors' affiliation

Correspondence to :

Pranayjeet Shinde

Department of Agricultural Engineering, Maharashtra Institute of Technology, Aurangabad (M.S.) India

Email : pranayshinde39@ gmail.com
ABSTRACT : Interest in developing food with nutritionally functional ingredient has been driven by the market potential for food. That can improve the health and wellbeing of consumers. Extruded snack (chakli) is traditional savory product was known as deep fat fried product. As per the results, its fat content is high. The variable sample were prepared by incorporating with the chickpea (Cicer arietinum L.), maize (Zea mays), Ragi (Eleusine coracana L.), green gram (Vigna radita) flour's extrusion cooking was carried out a single screw (Hand molder) and the frying temperature is $\left(180-200^{\circ} \mathrm{C}\right)$ for the 15 minute's the extrudate nutritional or the physical properties namely bulk density, water absorption index (WAI), oil absorption capacity, texture analysis were also analyzed. The orgaoleptic evaluation of extruded snack (chakli) sample were analyzed by panel list on a 9 point hedonic scale the results show that the composite flour chickpea, maize, ragi, green gram, pineapple pomace powder flourin the ratios of 48:15:15:20:2, respectively could be used to produce quality extrudate snack (chakli) with acceptable sensory properties.

KEY WORDS : Chemical, Physical property, Extrusion, Multigrain flours, Pineapple pomace powder, Sensory evaluation, Texture analysis

-HOW TO CITE THIS PAPER : Shinde, Pranayjeet and Dabhade, Surekha (2018). Development of extruded snack by using multigrain with pineapple pomace powder. Internat. J. Agric. Engg., 11(2) : 328-334, DOI: 10.15740/HAS/IJAE/11.2/328-334. Copyright@ 2018: Hind Agri-Horticultural Society. 